\title{
Further Pushing the Boundaries of Possibility
}

\author{
Stefan Oschmann
}

It's been quite some time since I worked in a laboratory as a scientist. Since then, my professional career has taken me on a very interesting journey. Yet, even after decades in executive management positions, I still enjoy leaving office and conference rooms behind to interact directly with researchers, whether in their laboratories or at conferences. Science still fascinates and amazes me. That is why the Curious 2018 Future Insight Conference was truly special for me.

In July 2018, around 1000 bright minds gathered in our home town of Darmstadt for the Curious 2018 Future Insight Conference to discuss the latest trends in science and technology. The topics and projects presented were cutting-edge. They showcased what humanity can achieve. I am very proud of the fact that we were able to welcome some of the world's most distinguished scientists and entrepreneurs, among them six Nobel laureates, including Frances Arnold, the winner of the Nobel Prize in Chemistry in 2018.

Curious 2018 was one of the highlights of our company's 350th anniversary celebrations. At the

The original version of this chapter was inadvertently published as non-open access. It has now been changed to open access with the copyright holder name "The Author(s)". The correction to this chapter is available at [https://doi.org/10.1007/978-3-030-16061-6_18]

S. Oschmann $(\bowtie)$

Chairman of the Executive Board and CEO

of Merck, Darmstadt, Germany conference and on many other occasions throughout our anniversary year, people I met asked me two questions. How has Merck managed to survive over such a long period of time? And how do you plan to continue this legacy? Even though our anniversary is now over, I want to take this opportunity to address these two questions.

\subsection{What Has Allowed Merck to Thrive for $\mathbf{3 5 0}$ Years?}

So what are the factors that have enabled Merck to grow for more than three and a half centuries? There is no silver bullet answer to this question. Certainly, many factors have contributed to our company's longevity. However, two stand out.

First, there's family ownership. In 1668, the aspiring pharmacist Friedrich Jacob Merck acquired a pharmacy in Darmstadt. That was the time when scientists such as Isaac Newton and Gottfried Wilhelm Leibnitz were revolutionizing the world of mathematics and science. The first thinkers of the Enlightenment were challenging the divine world order and embracing the concept of human self-determination. Ever since this era, the Merck family has controlled our company's development. They successfully steered it through three and a half centuries, including several major political and economic crises. This is a great entrepreneurial accomplishment that the Merck family can be very proud of. 
The second factor that has greatly contributed to the longevity of Merck is curiosity. The desire to learn and discover and to explore the new and unusual is a core part of our DNA. Hardly anyone embodies this as well as Emanuel Merck. He played a central role in the history of our company. Emanuel Merck took over the Merck pharmacy in 1816. He not only learned the pharmacy craft, as was common at the time, but also received extensive scientific training. His research focused on the field of phytochemistry, particularly on alkaloids. Scientific interest in these highly effective active plant ingredients increased considerably after Friedrich Wilhelm Sertürner had discovered morphine as an active substance in opium. Compared with the herbal preparations that were standard at the time, isolated alkaloids offered a decisive advantage: Physicians could dose them precisely; their effect in patients became calculable. Emanuel Merck succeeded in producing highly pure alkaloids that he provided to pharmacists, scientists, and physicians for further research. His products were well-received and demand grew, and soon he started supplying them to many European countries. Thanks to Emanuel Merck's passion for research and discovery and thanks to his curiosity, the pharmacy grew to become a research-driven industrial company.

Another prime example of the importance of curiosity is the story of liquid crystals. They were first discovered by an Austrian botanical physiologist in 1888. By the early twentieth century, Merck had already offered substances with liquid crystalline properties. Yet, demand was very low since apart from research, no one could conceive of any technical, large-scale applications. Eventually, the business was ended altogether and the story could have ended as well, but it didn't. Fast forward some decades to the 1960s, when a Merck scientist attended a scientific conference on liquid crystals in the USA. He returned convinced of the technology's economic potential. Together with a few colleagues, he started to work on this topic. The team encountered many skeptics who had doubts about the technology's potential. Protected by senior management, they carried on with their work. With tenacity and expertise, our scientists brought a first product line to market in 1969. This early technology was far from perfect. To function properly, these liquid crystals required a temperature of $80{ }^{\circ} \mathrm{C}$.

Eventually, Darmstadt-based researchers succeeded in mixing liquid crystals that worked at room temperature - an enormous advance. With this development, the technology was perfected for mobile applications. And in the 1990s, the market was ready: A huge order of $100 \mathrm{~kg}$ of liquid crystals came in from Japan. The reason for this? Tamagotchis! These handheld digital pets were very popular back then. Today, liquid crystals are the central technology in the displays of smartphones, computers, and TVs. Merck is the market leader - a position that we owe to a large degree to the curiosity of our scientists who pursued their passion for research and discovery over decades.

\subsection{A Vibrant Science and Technology Company}

Today, Merck is a vibrant science and technology company with around 52,000 employees in 66 countries around the world.

Our company comprises three distinct business sectors, each of which ranks among the technology leaders in its respective industry.

Our Healthcare business sector helps to create, improve, and prolong life. We deliver personalized treatments for serious diseases such as cancer and multiple sclerosis and enable people to achieve their dream of becoming parents. Our research activities focus on oncology, immuno-oncology, and immunology.

Our Life Science business sector empowers the scientific community. Our tools and solutions make research simpler, more exact, and help to deliver breakthroughs more quickly. Our discoveries have far-reaching impact, such as assuring people around the world that the food they eat is safe and the medicines they take are effective.

Our Performance Materials business sector helps to literally brighten the world around us with technologies such as the aforementioned liquid crystals and OLED materials. Our science is inside technologies such as semiconductor 
materials that are changing the way we access and display information and that are making future mobility safer, homes and devices smarter, and technology more sustainable.

Our business sectors engage in very different industries and markets. Yet they are firmly united by one single factor: science. That's at the heart of everything we do. Science drives the discoveries we make and the technologies we create.

\subsection{Curious Minds Dedicated to Human Progress}

We are curious minds dedicated to human progress. We believe in science as a force for good, a force that can help us to make a lasting difference in the lives of millions of people around the world.

Curiosity is a fundamental part of our identity. Yet we know that in order to make a positive difference in many people's lives, it must be firmly anchored in strong values. As majority owners, the Merck family has always ensured that Merck is a values-based company. Courage, achievement, responsibility, respect, integrity, and transparency shape our daily work, the way we engage with all our stakeholders and how we tackle future challenges.

With that in mind, how do we intend to ensure that our entrepreneurial legacy continues in the years to come?

Taking a step back and looking at the fundamental developments that are shaping our world, we see that science is having a great impact on people's lives. Over the past decades, mankind has achieved a lot through science. On average, we now live longer than ever before, global average life expectancy stands at 72 years. We are making good progress in fighting HIV, malaria, and some neglected tropical diseases. The proportion of people living in extreme poverty has fallen dramatically over the past decades - even though the world's population is growing steadily. Hundreds of millions of people have been lifted out of poverty. I see absolutely no reason why science and technology should not continue to further improve human life. In fact, I am convinced that there has never been a more exciting time for research than today.

Precision medicine can fundamentally change the way we not only treat but also prevent and intercept disease. Our understanding of the fundamental biological mechanisms of diseases is growing. Combining new molecular biological methods with technologies like artificial intelligence (AI) will help us to better understand disease and to develop entirely new ways of treating it. Very soon, physicians will be able to tailor medicines to patient needs even more precisely, eventually making the "one-size-fits-all" approach obsolete.

At the same time, we are seeing emerging players, for example, from the digital world, entering the healthcare sector. New technologies, for example, those that connect biological systems, such as those found in the human body, with the digital world hold great promise. They will permit much better monitoring and management of health.

At the same time, the way $R \& D$ works is changing as well. Equipment costs are falling. Knowledge is broadly available. The so-called crowd can be both a congenial co-researcher and financier. All of this will empower smaller players who will increasingly have the means to transform their ideas into real products.

A big driver of this is the fact that more and more devices are connected with one another and to the Internet. Thanks to new generations of microchips and sensors, we are just starting to feel the impact of the Internet of things (IoT). It will not only make scientific work easier and faster, but also transform many more aspects of our daily lives. It will boost the electronics industry. And it will help us to generate new data which we can use to build entirely new business models.

\subsection{Pushing the Boundaries of Possibility}

At Merck, we are shaping all these trends and developments. Our more than 7000 curious researchers are pushing the boundaries of what's 
possible. Hardly any other company unites so many disciplines and such broad scientific expertise under one roof.

In our Healthcare business sector, we are aiming to become a global specialty innovator. We want to deliver innovative specialty medicines that make a lasting difference in patients' lives, for example, new and very precise therapies to fight cancer.

In our Life Science business sector, we seek to further empower researchers and biotech companies by developing new technologies, for instance, genome-editing tools. These will give researchers around the world entirely new ways to further enhance their understanding of biology.

In our Performance Materials business sector, we want to excite our customers with innovative high-tech solutions. Our technologies enable the electronics industry to produce faster and smaller microchips - for instance, specialty chemicals that allow manufacturers to apply insulating material and metal layers with the thickness of a single atom to semiconductor wafers.

We are working hard to drive new technologies. Yet to ensure lasting entrepreneurial success in an era of exponential technological change, we know that we cannot simply rely on our established business sectors. We must and we will go further. Given the very diverse set of competencies and scientific expertise, we aim to develop groundbreaking new technologies at the interfaces of as well as beyond our three business sectors.

That's the mission of our new Innovation Center. Here, we are helping ideas to grow and turning them into viable new businesses. Merck employees from all business sectors can team up with external entrepreneurs to develop innovations beyond our current boundaries. The focus of our activities lies on three innovation fields: "Biosensing and Interfaces" focuses on the interface between the biological and the digital world. "Clean Meat" is about alternative ways of meat production that require less resources and are more sustainable. And "Liquid Biopsy Technologies" aims to develop new technological solutions to overcome unresolved challenges in the liquid biopsy workflow as well as new applications beyond cancer.

Another important way to drive innovation is through partnerships. As a science and technology company, we want to be part of the global scientific community. This is why we are collaborating with leading research institutions such as the Weizmann Institute in Israel.

But partnerships extend beyond the academic sector. We are also working closely and developing new technologies with other leading technology companies. A prime example is Syntropy, a new joint venture which we plan to establish together with Palantir Technologies. Its goal is to unlock the potential of data in cancer research to facilitate scientific collaboration. Much of the vast amount of data that we generate every day is inaccessible to the researchers who might benefit from it the most. With Syntropy, we want to overcome this problem and develop a new platform that allows scientists to access and work with other scientists' data in a secure and transparent manner. At the same time, scientists will always have control over their data.

\subsection{Making Curiosity Thrive}

Curiosity always has and will continue to play a major role at Merck. As a science and technology company, we must ensure that it can thrive and that our researchers have the best possible work environment.

Therefore, to define curiosity more precisely, we have developed a model consisting of four key pillars. According to this model, curiosity comprises "joyous exploration" or the pleasure of seeking out new information and of learning and growing. It also encompasses "deprivation sensitivity," the unpleasant state of uncertainty which persists until we have closed the gap between what we know and what we want to know. The third pillar is "stress tolerance," the willingness to accept the distress that arises from exploring uncertain terrain. And lastly, curiosity of course implies an openness to other people's ideas, an appreciation of different perspectives. 
Since curiosity plays a critical role in today's fast-paced environment, we surveyed over 3000 workers from China, the USA, and Germany across five industries. The aim was to gain insights that will help further unlock the potential of curiosity to drive innovation. You can find the detailed results in our "2018 State of Curiosity" report on our Web site (curiosity.merckgroup.com). Our study showed that curiosity is malleable; it can be taught and cultivated. If actively encouraged and nurtured throughout an organization, curiosity can accelerate idea generation and enable us to address global challenges and change with efficiency and precision. In my view, that's good news.

So what are we specifically doing to make curiosity thrive and provide our R\&D staff with the best possible work environment?

There is no doubt that the days of the genius working on an idea in solitary confinement in a laboratory are long gone - if that was ever the case in the first place. Science is teamwork, and a company's duty is to provide scientists with an environment that allows them to focus on what matters most: research.

We want scientists to see Merck as a great place to work. Therefore, we are continuously looking at ways to help our researchers to deliver their very best. The steps we have taken in recent years include measures such as adapting feedback mechanisms to the specific environment of R\&D units, opening new career paths for scientists and establishing a company-wide "science network" to help our researchers collaborate and share ideas.

Pushing the boundaries of possibility in our industries, creating new technology ventures beyond our current scope and providing our scientists with the best possible work environment are key in making sure that Merck successfully continues its more than 350-year history. But as a values-based company, we know that our responsibility extends beyond the boundaries of our business activities. We are convinced that science and technology will greatly help us to tackle some of humanity's greatest challenges in the years and decades to come.

\subsection{Helping Tackle Global Challenges}

These threats are evident. We need to prepare ourselves for global pandemics. Antimicrobial resistance poses one of the most pressing global health challenges. We need to ensure safe and sufficient nutrition for a world that, according to the United Nations' estimates, will be home to almost 10 billion people in 2050 . And of course, we are in desperate need of finding new clean sources of energy. None of these are core business areas for Merck. Yet as a science and technology company, we hold a special responsibility to encourage research in these fields, which can lead to the breakthrough technologies we urgently need.

This is why we decided to launch the Future Insight Prize, which we publicly announced for the first time at Curious 2018. With the prize, we want to stimulate innovative solutions to help solve the global challenges described above. We intend to grant up to one million euros annually for the next 35 years. The first Future Insight Prize will be awarded in summer 2019 to researchers who have made important contributions in the field of pandemic preparedness. Potential award recipients will be selected by a high-ranking jury of internationally renowned scientists and executives from Merck and our cooperation partners worldwide.

\subsection{Let's Unleash the Potential of Science and Technology}

We have every reason to believe that science and technology will further drive human progress. At Merck, we want to help shape this change. We believe that scientific exploration, driven by curiosity, and responsible entrepreneurship are key to technological advances that will benefit us all. Therefore, we will continue to push the boundaries of what's possible and to create opportunities for everyone. This is what drives us. This is what we work for. So let's unleash the potential of science and technology - as curious minds, dedicated to human progress. 
Open Access This chapter is licensed under the terms of the Creative Commons Attribution-NonCommercial 4.0 International License (http://creativecommons.org/licenses/bync/4.0/), which permits any noncommercial use, sharing, adaptation, distribution and reproduction in any medium or format, as long as you give appropriate credit to the original author(s) and the source, provide a link to the Creative Commons license and indicate if changes were made.
The images or other third party material in this chapter are included in the chapter's Creative Commons license, unless indicated otherwise in a credit line to the material. If material is not included in the chapter's Creative Commons license and your intended use is not permitted by statutory regulation or exceeds the permitted use, you will need to obtain permission directly from the copyright holder. 